\title{
Removal of Hardness from Groundwater by Synthetic Resin from Waste Plastics
}

\author{
Prapat Pentamwa, Wipasinun Thipthara, and Suparat Nuangon
}

\begin{abstract}
The capacity of waste polystyrene plastics for hardness groundwater removal was investigated in this study. The wastes of polystyrene were prepared from foam of food packaging and air bubble plastic. They were synthesized into active adsorbent cationic resin. The water hardness was pumped through the designed column with combination of made resin and sand-gravel filters for groundwater treatment. The results revealed that the hardness removal efficiency of added made resins in the system was higher than no added resin $(43 \%$ vs $12 \%)$ and they were below the acceptable Thailand standard for groundwater drinking water of $300 \mathrm{mgCaCO} / \mathrm{L}$. However, there were no difference in term of hardness efficiency capability for different types of polystyrene plastics and the thickness of resin used in the study.
\end{abstract}

Index Terms-Hardness water, groundwater, resin, waste plastics, Nakornratchasima.

\section{INTRODUCTION}

Water hardness is the major amount of calcium and magnesium cations in water. Hardness is mostly expressed as milligram of calcium carbonate $\left(\mathrm{CaCO}_{3}\right)$ equivalent per liter and also can be mentioned in term of carbonate (temporary) and noncarbonated (permanent) hardness. The hardness in water is naturally occurring in groundwater which weathering of limestone, sedimentary rock and calcium bearing minerals. They are also present locally from industrial effluent such as chemical and mining industry or the excessive use of lime to the soil in agriculture field.[1,2] Hardness concentrations in natural water are up to 100 $\mathrm{mgCaCO}_{3} / \mathrm{L}$, depending on the associated sources, and are presenting in the range of $10-500 \mathrm{mgCaCO}_{3} / \mathrm{L}$ in drinking water.[2]. In Thailand, the groundwater quality standard for drinking purposes of total hardness as $\mathrm{CaCO}_{3}$ is set to less than $300 \mathrm{mg} / \mathrm{L}$ for suitable allowance guideline.[3] The water quality hardness standard in Thailand is divides hardness classifications into following categories: soft water, medium water, and hard water as shown in Table I. However, there is no guideline value for total hardness in drinking water from World Health Organization.[2]

Hardness water is mainly an aesthetic concern because of the unpleasant taste and reduces the ability of soap to produce lather. It is also causing scale formations in pipes and on distribution system [1].

Manuscript received October 10,2011, revised October 12, 2011.

Prapat Pentamwa, Wipasinun Thipthara and Suparat Nuangon are with the School of Environmental Health, Institute of Medicine, Suranaree University of Technology, Nakornratchasima, 30000. Thailand (e-mail: prapat@sut.ac.th; pong-wt@hotmail.com; krapay_0724@hotmail.com).
TABLE I: THE HARDNESS WATER CATEGORY

\begin{tabular}{lc}
\hline \hline Hardness category & Equivalent concentration of $\mathrm{CaCO}_{3}$ \\
\hline Soft water & $0-75 \mathrm{mg} / \mathrm{L}$ \\
Medium hard water & $75-150 \mathrm{mg} / \mathrm{L}$ \\
Hard water & $150-300 \mathrm{mg} / \mathrm{L}$ \\
very hard water & $300 \mathrm{mg} / \mathrm{L}$ and greater \\
\hline \hline
\end{tabular}

Due to the high levels of hardness in water, people may become unacceptable with unaccomplished taste. Therefore, the most common method to remove of hardness in household level for drinking and ground water utilization is boiling. The nanofiltration can be also used for hardness removal from groundwater. It is an effective process in term of higher recovery for hardness removal.[4]. Presently, nanotechnology such as zero valent iron and carbon nano tube is promising technology for groundwater remediation for drinking and reuse. Nanoremediation has the potential to clean up large contaminate site and reducing the contaminant concentration to near zero. [5].

However, there are various others methods for calcium and magnesium hardness removal from groundwater such as reverse osmosis, ion exchange, combination of ultrasound and ion exchange and chemical treatment with lime-soda ash method. $[6,7,8]$ The ion exchange process is extensively used and also the most effective methods to remove hardness in groundwater. It is contained with resin that calcium and magnesium ion can be exchanged for sodium and potassium ions. The commercials resins are presently used in individual home and industrials purposes to remove the ionic impurity in water. The ion exchange resin can be either natural green sand or synthetic zeolite resin, known as polystyrene resin which is most commonly used now. Polystyrene is thermoplastic substances that are solid state in room temperature. The foam polystyrene products are ubiquitous used as insulation, packaging materials, and foam drink cups. However, they are environmental impact concern for the usage of foam polystyrene packaging. The discarded polystyrene does not biodegradable and also resist to photolysis. The study for polystyrene products recyclable is very limited. One investigation study shown the possibility used of polystyrene white coffee cup converted into adsorbent resin to remove hardness in water.[9] In the present study was to investigate the use of waste polystyrene foam and plastics such as foam packaging for food and air bubble plastics as synthetic resins with a combination of packed sand-gravel filters in columns system to remove hardness in groundwater. 


\section{MATERIALS AND METHODS}

\section{A. Study Area and Groundwater Samples}

This experiment was carried out by using groundwater from Surathumpitak school well number MY4538 in the area of Nakornratchasima province of Thailand. Groundwater was collected in March 2011. The province is located at the northeastern part of Thailand where the area is covers more than one-third of the country, a so called "Khorat Plateau" (Fig. 1). It is one of the main physiographic regions of Thailand.[10] The northeast region has been concerned with water supply consumption due to the long dry period of about 8 months per year and has low level of rainfall intensity. The surface water is also limited causing insufficient water for domestic and agriculture uses. Therefore, groundwater is play an important role for water supply in northeast Thailand.

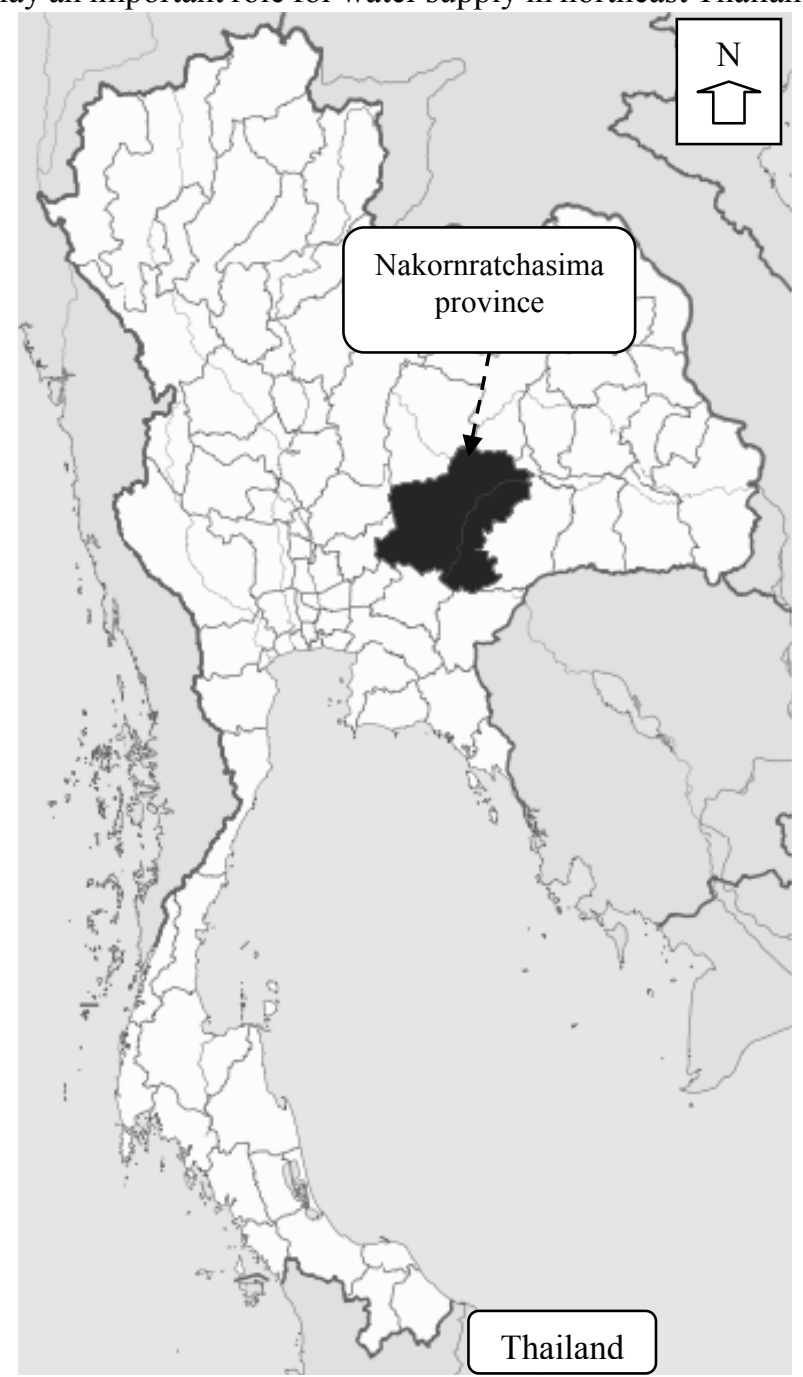

Note: This map is not to scale.

Fig. 1. The map of study area

\section{B. Material Preparation}

The synthetic resins were prepared from wastes polystyrene foam for food packaging and air bubble polystyrene plastics. The method for resin preparation was applied from Bekri-Abbes (2008).[9] Briefly, both of polystyrene foam and plastics were crushed to obtained size of $0.2-0.3 \mathrm{~cm}^{2}$ for the total weight of about $30 \mathrm{~g}$. Each $5 \mathrm{~g}$ of raw material was transferred in flask with $100 \mathrm{~mL} \mathrm{95 \%}$ sulfuric acid and left to react under room temperature till the reaction period is completed. The slurry was filtered with a funnel and washed with $250 \mathrm{~mL}$ of distilled water for ten times. The $\mathrm{pH}$ paper was use to check the residual sulfuric acid in washed water to ensure the removal from resin. The resin was then dried at $40{ }^{\circ} \mathrm{C}$ for $30 \mathrm{~min}$. The neutralization process was introduced by stirring the resin for $2 \mathrm{~h}$ at $500 \mathrm{ml}$ $1 \mathrm{M} \mathrm{NaCl}$ solution. This process aims to convert the sulfonated polymer resin into its $\mathrm{Na}^{+}$form. The ion exchange capacity was evaluated by measuring the concentration of $\mathrm{H}^{+}$ which was exchange with $\mathrm{Na}^{+}$when acid form of sulfonated polystyrene was equilibrated with $\mathrm{NaCl}$ solution. The dry polymer $(5 \mathrm{~g})$ in the $\mathrm{H}^{+}$form was placed $100 \mathrm{~mL}$ of $0.2 \mathrm{M}$ $\mathrm{NaCl}$ solution and shaken for $2 \mathrm{~h}$, the amount of $\mathrm{H}^{+}$released by the polymer was determined by the titration with $0.01 \mathrm{M}$ $\mathrm{NaOH}$. The finished synthetic resin from food packaging and bubble air plastics are showed in Fig.2. The both fine sands and gravels were used in the study as filter material in the packed column with the size diameter range of $0.125-0.250$ $\mathrm{mm}$ and 4.0-8.9 mm, respectively (Fig. 3).

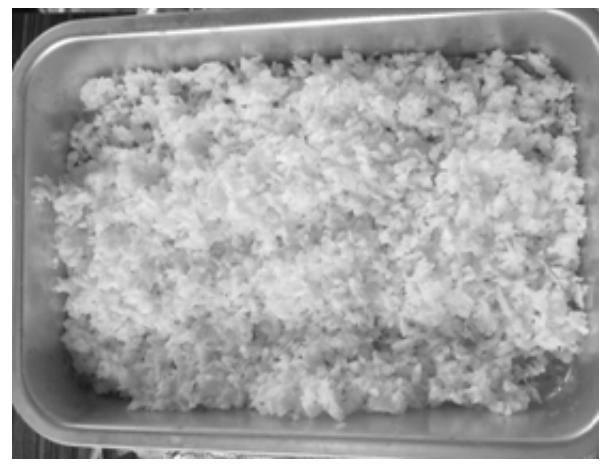

(a) Synthetic resins from food packaging

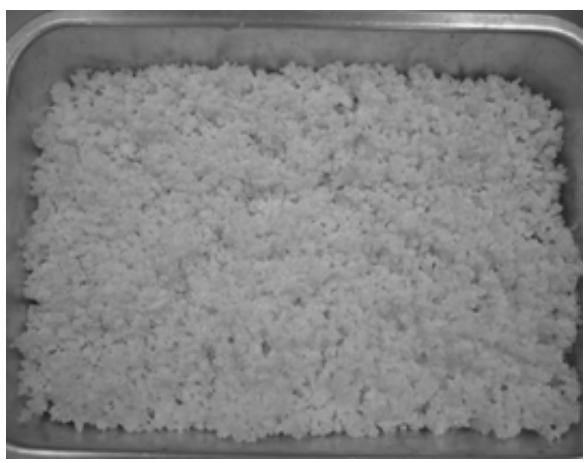

(b) Synthetic resins from bubble plastics

Fig. 2. The synthetic resin from (a) food packaging and (b) bubble air plastics

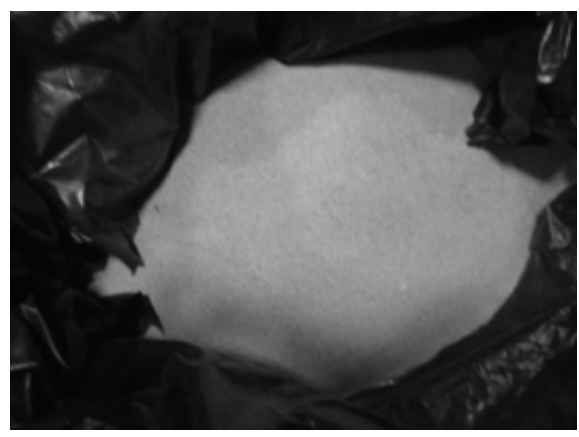

(a) Fine sand 


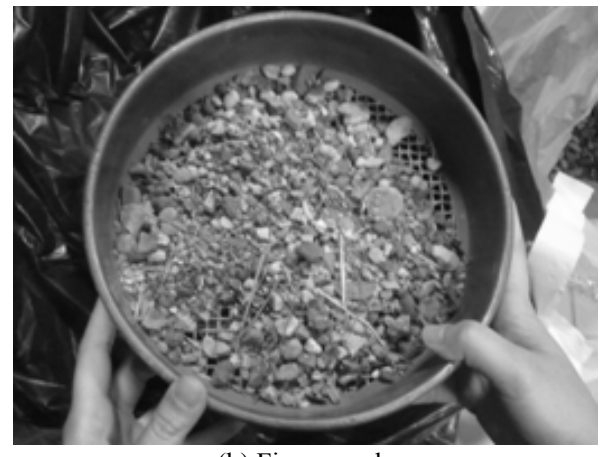

(b) Fine gravels

Fig. 3. The filters used in the column from (a) fine sand and (b) fine gravels

\section{Hardness Removal System}

This study was a pilot-experiment study. The treated groundwater samples were produced by the following treatment columns including top packed made resin and then fine sand and fine gravels filters. The detail experimental setup of the study was illustrated in Fig 4 . The material filters filled in experimental column are illustrated in Table II. The experimental train was continuously run with time through the separations of 5 packed columns with different thickness of filters. Each column was made from polyvinyl chloride plastic with $10 \mathrm{~cm}$ diameter and $60 \mathrm{~cm}$ long column. The groundwater was pumped through columns with flow rate of $1 \mathrm{~L} / \mathrm{min}$ for $1 \mathrm{~h}$. The raw groundwater and effluents water of pre-and post experiment column were measured for temperature, $\mathrm{pH}$, conductivity and total hardness parameters. The total hardness analysis was measured using the EDTA titrametric method in according to the Standard methods (1998). [11]

TABLE II: THE MATERIALS IN THE EXPERIMENTAL COLUMN

\begin{tabular}{lcccc}
\hline \hline Column & Bubble plastic resin & Foam resin & Fine sand & Fine gravels \\
\hline Control & none & none & $600 \mathrm{~g}$ & $100 \mathrm{~g}$ \\
I & none & $329.5 \mathrm{~cm}^{3}$ & $600 \mathrm{~g}$ & $100 \mathrm{~g}$ \\
II & none & $785 \mathrm{~cm}^{3}$ & $600 \mathrm{~g}$ & $100 \mathrm{~g}$ \\
III & $329.5 \mathrm{~cm}^{3}$ & none & $600 \mathrm{~g}$ & $100 \mathrm{~g}$ \\
IV & $785 \mathrm{~cm}^{3}$ & none & $600 \mathrm{~g}$ & $100 \mathrm{~g}$ \\
\hline \hline
\end{tabular}

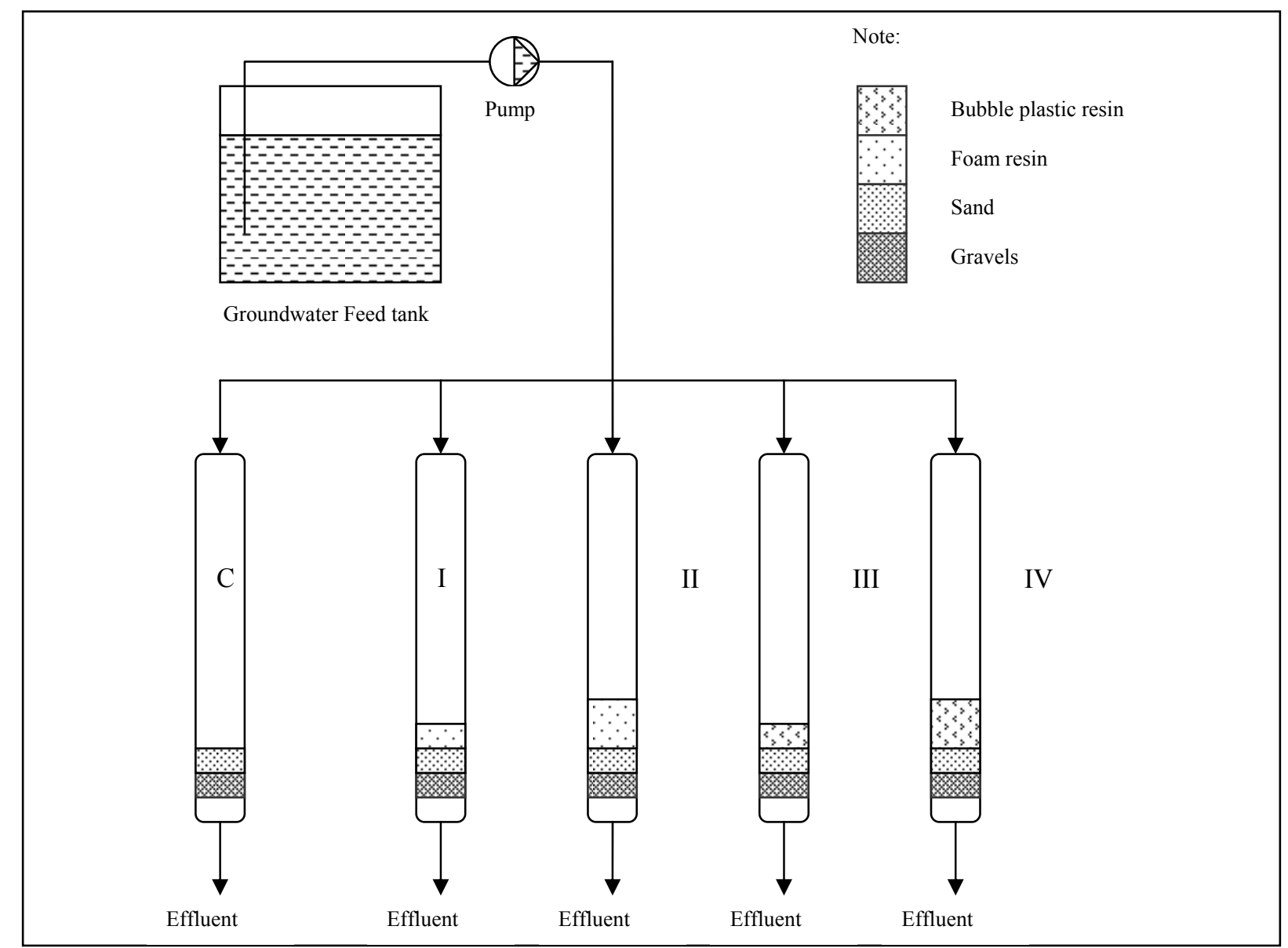

Remark: C is the control column, Column I, II, III, and IV are the experimental columns.

Fig. 4. The experiment set up for continuous flow of packed sand-gravel filter and synthetic resins from waste plastics.

\section{RESULTS AND DISCUSSION}

\section{A. Groundwater Quality}

The results of raw ground water quality are shown in Table III. The total hardness was a major parameter of groundwater which is averaged of $440 \mathrm{mg} \mathrm{CaCO}_{3} / \mathrm{L}$. It is noted that the total hardness as $\mathrm{CaCO}_{3}$ was considered to be very hard water and also was above the suitable allowance according to the Thailand national standard for groundwater quality for drinking purposes which is set to less than $300 \mathrm{mg} / \mathrm{L}$. 
Although there have been limited epidemiology studies report shown the relationship between hardness in water and health effect such as cardiovascular disease.[2] However, other study found the correlation between carcinogenicity Trihalomethane and $\mathrm{Mg}$ intake via drinking water [12] and water hardness may increase the risk of atopic dermatitis among elementary school children in Japan. [13]

\begin{tabular}{lcccc}
\multicolumn{5}{c}{ TABLE III: CHARACTERISTICS OF GROUNDWATER } \\
\hline \hline Samples & $\begin{array}{c}\text { Total } \\
\text { Hardness } \\
\left(\mathrm{mgCaCO}_{3} / \mathrm{L}\right)\end{array}$ & $\mathrm{pH}$ & $\begin{array}{c}\text { Temperature } \\
\text { Conductivity }\end{array}$ & $\begin{array}{c}\text { Com } \\
\left({ }^{\circ} \mathrm{C}\right)\end{array}$ \\
\hline I & 440 & 6.73 & 25.6 & 853 \\
II & 440.7 & 6.69 & 25.6 & 853 \\
III & 440 & 6.83 & 25.6 & 855 \\
\hline $\begin{array}{l}\text { Average } \pm \\
\text { SD }\end{array}$ & $440 \pm 0.3$ & $6.75 \pm 0.0$ & 25.6 & $854 \pm 1.1$ \\
\hline \hline
\end{tabular}

However, the problem of hardwater is majority on home nuisance with the high soups and detergents consumption for cleaning tasks. Hardwater also contributed to inefficient and costly operation of water-using appliances. The water hardness are above $200 \mathrm{mg} / \mathrm{L}$ may cause scale deposition in the distribution system. [2] In northeastern Thailand, the groundwater resources are very important due to a shortage of water in the long occasionally drought period per year.
Moreover, groundwater quality problem in Thailand is also predominantly shown the high constituents of chloride, sulphate and iron substances in groundwater. For the northeastern Thailand, the main problem is high level of chloride and hardness contents in groundwater quality. [10]

\section{B. Hardness Removal Efficiency}

The determination results of ground water quality through experiment designed column are given in Table IV. The total hardness treated water from control column (no packed resin) was averaged of $386.7 \mathrm{mgCaCO}_{3} / \mathrm{L}$. It can be seen that it was exceeded the Thailand standard of $300 \mathrm{mgCaCO}_{3} / \mathrm{L}$. For the column I, II, III and IV, the total hardness concentrations of treated water were not significant different and they fell in the range of $248-250 \mathrm{mgCaCO}_{3} / \mathrm{L}$. It can be observed that the level of total hardness parameters for the treated water of all the design packed column were acceptability below the Thai standard for groundwater drinking water except for the control column. The efficiency of filter column hardness removal system is also shown in Table V. It is indicated that the difference in hardness removing ability with filled made resin and no-filled resin. The hardness removal efficiencies of added made resins in the system were higher than no added resin $(43 \%$ vs $12 \%)$. However, there were no different for both types of polystyrene plastics and the thickness of resin in term of hardness efficiency capability.

TABLE IV: HARDNESS REMOVAL OF GROUNDWATER BY COMBINATION OF SAND FILTER AND SYNTHETIC RESIN

\begin{tabular}{lccccc}
\hline \hline Samples & \multicolumn{3}{c}{ Total Hardness, $\mathrm{mg} \mathrm{CaCO}_{3} / \mathrm{L}$} \\
\cline { 2 - 6 } & Control column & Column I & Column II & Column III & Column IV \\
\hline Raw groundwater & 440 & 440 & 440 & 440 & 440 \\
Treated water I & 388 & 250 & 248 & 252 & 246 \\
Treated water II & 384 & 252 & 250 & 250 & 248 \\
Treated water III & 388 & 248 & 246 & 248 & 252 \\
\hline Average \pm SD & $386.7 \pm 2.3$ & $250 \pm 2$ & $248 \pm 2$ & $250 \pm 2$ & $248.7 \pm 3$ \\
\hline \hline
\end{tabular}

TABLE V: HARDNESS REMOVAL EFFICIENCY OF GROUNDWATER BY COMBINATION OF SAND FILTER AND SYNTHETIC RESIN

\begin{tabular}{lcccc}
\multicolumn{2}{c}{ TABLE V: HARDNESS REMOVAL EFFICIENCY OF GROUNDWATER BY COMBINATION OF SAND FILTER AND SYNTHETIC RESIN } \\
\hline \hline Samples & \multicolumn{3}{c}{ Removal efficiency (\%) } \\
\cline { 2 - 5 } & Control column & Column I & Column II & Column III \\
\hline Treated water I & 11.82 & 43.18 & 43.64 & 43 \\
Treated water II & 12.73 & 42.73 & 43.18 & 43.18 \\
Treated water III & 11.82 & 43.64 & 44.09 & 43.64 \\
\hline Average & 12.12 & 43.18 & 43.64 & 43.18 \\
\hline \hline
\end{tabular}

\section{CONCLUSION}

This study shows the possibility to use the waste plastic as a synthetic resin to remove hardness in groundwater. The designed hardness removal system is expecting to be suitable for groundwater household use. Further study should be conducted to investigate the recovery efficiency of made resin as well as be examined others polystyrene plastics to be a potential polymer resin to remove hardness in water.

\section{ACKNOWLEDGMENT}

The authors are express thanks to the school of environmental health and the scientific and technology equipment canter of Suranaree University of Technology, for providing analytical equipment for water analysis. 


\section{REFERENCES}

[1] British Columbia of Canada. Hardness in groundwater fact sheet. The British Columbia groundwater association. 2007.

[2] WHO. Hardness in drinking water, Background document for development of WHO guidelines for Drinking water quality. World Health Organization. 2003.

[3] PCD, the Pollution Control Department of Thailand. Water Quality Standard. 2011. Retrieved on May 2011 from website: www.pcd.go.th

[4] Schaep, J., Bruggen, B., Uytterhoeven, S., Croux, R.. (1998). Removal of hardness from groundwater by nanofiltration. Desalination 119, 295-302

[5] Rajan, C.S. 2011. Nanotechnology in groundwater Remediation. International Journal of Environmental Science and Development. 22 (30 182-186.

[6] M.H. Entezari, and M. Tahmasbi. Water softening by combination of ultrasound and ion exchange. Ultrasonic Sonochemistry. 2009, 16:356-360.

[7] S. Cinar abd B. Beler-Baykal. Ion exchange with natural zeolites: an alternative for water softening?. 2005. Water Science \& Technology. 51(11): 71-77.
[8] Entezari, M., Tahmasbi, M. 2011. Water softening by combination of ultrasound and ion exchange. Ultrasonics Sonochemistry 16, 356-360

[9] I. Bekri-Abbes, S. Bayoudh, M. Baklouti. The removal of hardness of water using sulfonated waste plastic. 2008. Desalination. 222: 81-86.

[10] S. Wonsawat, O. Dhanesvanich, S. Panjasutaros. Groundwater resources of Northeastern Thailand. The National conference on "Geologic resource of Thailand: potential for future development" 17-24 November 1992, Department of Mineral Resources, Bangkok, Thailand.

[11] Standard methods for the Examination of water and wastewater. $20^{\text {th }}$ edition, American Public Health Association/American Water Work Association/Water Environmental Federation, Washington DC, USA.1998.

[12] Chiu ,H., Tsai ,S., Wu, T., Yang, C. 2010. Effect modification of the association between trihalomethanes and pancreatic cancer by drinking water hardness: Evidence from an ecological study. Environmental Research. 110, 513-518

[13] Miyake, Y., Yokoyama, T., Yura, A., Iki, M., and Shimizua, T. 2004. Ecological association of water hardness with prevalence of childhood atopic dermatitis in a Japanese urban area. Environmental Research 94, 33-37 